\title{
Unusual Cause of Hypoxemia
}

\section{Sushil Upadhyay*}

Rama Medical College and Hospital, Pulmonary Medicine, India

\author{
Abstract \\ Unusual cause of hypoxemia is presented in a 12 year old boy of Iraqi national.
}

Keywords: Hepatopumonary syndrome (HPS); Intrapulmonary vascular dilatation (IPVD); Liver transplantation (LT)

\section{Introduction}

Hepatopulmonary syndrome (HPS) is a rare cause of hypoxemia. HPS is characterized by intrapulmonary vascular dilatations causing right-to-left shunting, which leads to a range of arterial oxygenation abnormalities in patients with liver disease [1]. HPS has been reported to be present in $4 \%$ to $32 \%$ of adult patients with end-stage liver disease [2] and in $9-20 \%$ of children [3].

Cirrhosis is the most common condition associated with HPS. However, HPS has been reported in association with other liver disorders, including noncirrhotic portal hypertension, alpha-1 antitrypsin deficiency, Wilson disease, Budd-Chiari syndrome and acute and chronic viral hepatitis [4,5]. The cause of liver disease leading to portal hypertension does not seem to affect the development of HPS.

Liver transplantation is the only therapeutic option of proved benefit, and it can result in substantial improvement or total resolution in postoperative gas exchange [6]. However, the postoperative mortality rate of patients with severe hypoxemia before transplantation has been high [7]. Patients with a baseline $\mathrm{PaO}_{2} \leq 50 \mathrm{~mm} \mathrm{Hg}$ have been associated with a poor survival rate [6]. We describe a rare case of a child presenting with unexplained hypoxemia in asymptomatic liver disease, revealing HPS on further investigation.

\section{Case Report}

A 12 year old boy from Iraq presented to our hospital with history of breathlessness, bluish discoloration of lips, tongue and extremities for last nine months. Progressive effort intolerance was reported by the parents. There was no history of fever, cough, sputum or wheezing. On examination the boy looked emaciated, assuming supine position with breathing rate of 32 per minute (Figure 1). He had central and peripheral cyanosis with grade III digital clubbing (Figure 1c). His $\mathrm{spO}_{2}$ on room air was $52 \%$. With oxygen supplementation via simple mask it improved to suboptimal level of $82 \%$ and oxygen saturation with non rebreathe mask was 93\% (Figure 1a). Chest examination revealed normal breath sounds. Precordial examination was normal without any murmur. Non tender hepatomegaly was noted on abdominal examination. Laboratory parameters were grossly unremarkable except for mildly deranged liver function (Bilirubin: 1.2/0.4; AST/ALT/ALP: 104/68/228). Haemoglobin chromatography was normal. Coagulation profiles, serum ceruloplasmin, alpha-1 antitrypsin, antinuclear antibodies (ANA), and antineutrophil cytoplasmic antibodies (ANCA) were all normal.ABG (Figure $2 \mathrm{a}$ and $2 \mathrm{~b}$ ) was consistent with hypoxemic respiratory failure with increased alveoarterial (A-a) gradient. Chest Xray (Figure 3a) showed pulmonary congestion in lower lung fields and so was revealed by CT scan chest (Figure 3b). Transthoracic echocardiogram was unremarkable. In view of no past history of respiratory illness and normal lung examination and non-contributory chest skiagram cause of hypoxemia needed further evaluation. Ultrasound abdomen was remarkable for hepatomegaly with coarse echotexture, dilated splenoportal axis and portosystemic collaterals. CT pulmonary angiogram was normal. CT abdomen revealed enlarged liver with coarse architecture consistent with hepatic cirrhosis (Figure $4 \mathrm{a}$ and $4 \mathrm{~b}$ ). Echocardiogram with agitated saline bubbles revealed entry of bubbles in left atrium four cardiac cycles after it appeared in right atrium. Hepatopulmonary syndrome was thus concluded as the cause of hypoxemia.

\section{Discussion}

Hepatopulmonary syndrome is a rare complication of liver disease in pediatric age group. Poor oxygenation with no major abnormalities detected from chest imaging and accidental discovery of abnormal liver architecture were the best diagnostic clues in this case.

HPS was first described in 1977 by Kennedy and Knudson [8]. The

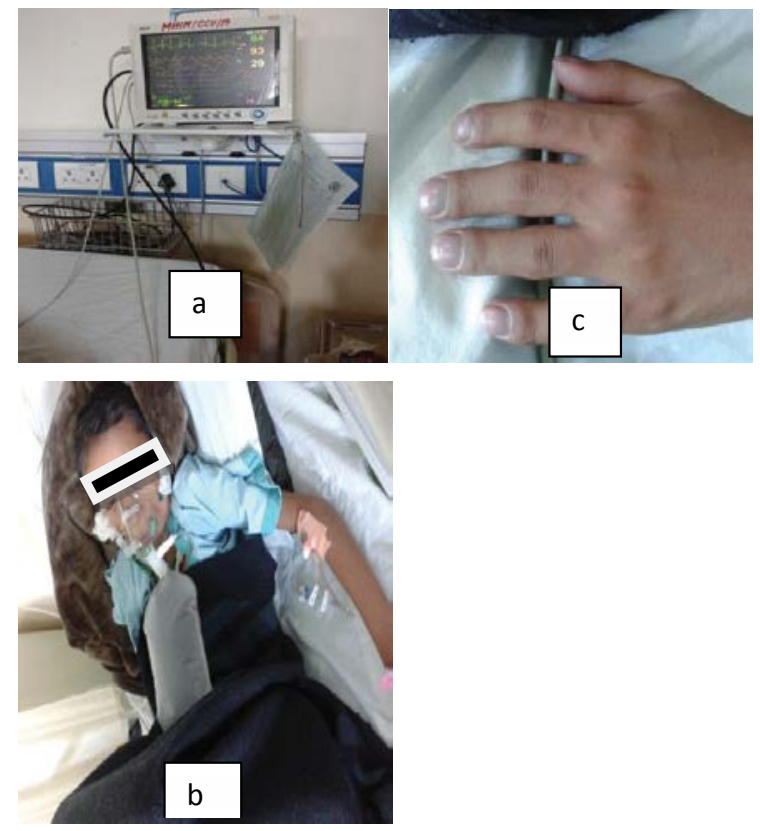

Figure 1: (a-c) Oxygen saturation shown as $93 \%$ on with oxygen through non rebreather mask. Cyanosis and digital clubbing

*Corresponding author: Sushil Upadhyay, Asistant Professor, Rama Medical College and Hospital, Pulmonary Medicine, H 104 Swarn Residency, 132 GT Road, Sahibabad, Ghaziabad, Uttar Pradesh 201005, India, Tel: 919899393006 ; Fax: 911222327311; E-mail: skupadhyay2002@rediffmail.com

Received June 11, 2015; Accepted July 15, 2015; Published July 20, 2015

Citation: Upadhyay S (2015) Unusual Cause of Hypoxemia. J Pulm Respir Med 5 279. doi:10.4172/2161-105X.1000279

Copyright: @ 2015 Upadhyay S. This is an open-access article distributed under the terms of the Creative Commons Attribution License, which permits unrestricted use, distribution, and reproduction in any medium, provided the original author and source are credited. 


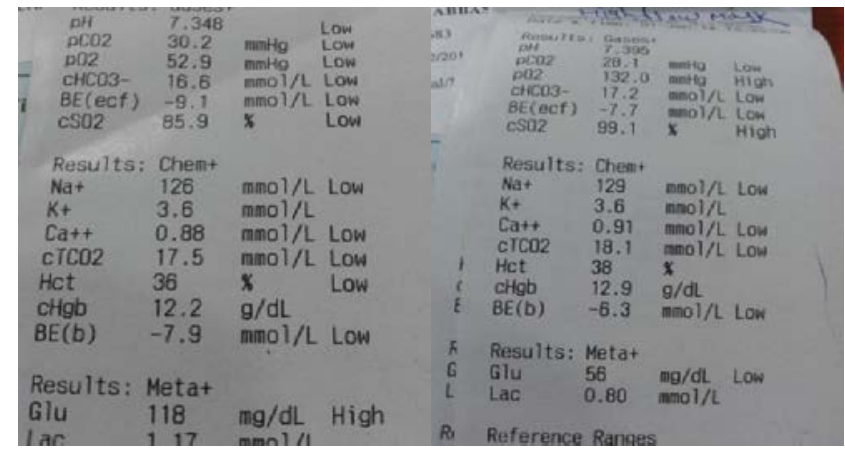

Figure 2: Arterial blood gases on ambient air (a) and on oxygen with nonrebreather mask (b).

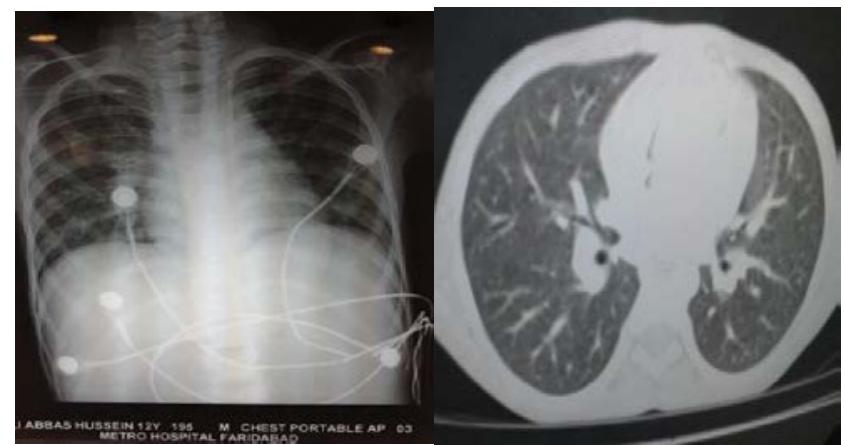

Figure 3: (a) Xray and (b) CT Chest: Congested basal area of lungs

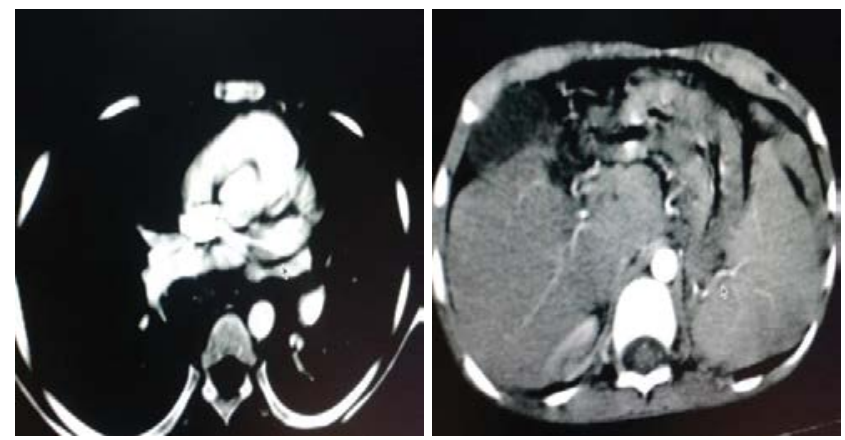

Figure 4: $(a$ and b) Normal CT pulmonary angiogram and coarse architecture of enlarged liver.

currently accepted diagnostic criteria for HPS are (1) presence of portal hypertension or liver failure, (2) decrease of arterial $\mathrm{PO}_{2}\left(\mathrm{PaO}_{2}<70 \mathrm{~mm}\right.$ $\mathrm{Hg}$, or increased age-corrected $\mathrm{A}-\mathrm{a} \mathrm{PO}_{2}$ gradient and (3) presence of intrapulmonary vascular disease(IPVD) producing an intrapulmonary shunt. The third one is the hallmark of HPS and is probably secondary to portal hypertension, producing a right-to-left intrapulmonary shunt [1]. HPS primarily affects the peripheral (precapillary and capillary) branches of the pulmonary vascular tree at the lung bases.

The clinical presentation includes exertional dyspnea, clubbing, cyanosis, spider angiomas and worsening of dyspnea as patient moves from the supine to standing position (platypnea) [7]. Chest radiograph abnormalities may be subtle and may mimic interstitial lung disease that reflects diffuse intrapulmonary vascular dilatation. Chest CT scanning can identify the discrete lesions that are most commonly seen in the periphery and lung bases. There appears to be no gender, race or hepatic disease relationship with HPS [9].

The most striking findings of the present case were digital cyanosis and clubbing with severe hypoxemia. Findings on physical examination of the chest were unremarkable. The patient did not elicit platypnea and orthodeoxia (reduced $\mathrm{PO}_{2}$ when changing from a supine to an upright position) that has been reported in the majority of patients with HPS [7].

The existence of pulmonary vascular dilatations can be determined using either contrast enhanced transthoracic echocardiography (qualitatively) or $99 \mathrm{~m}$ Tc macroaggregated albumin (99mTc MAA) lung perfusion scanning with brain uptake imaging (quantitatively) [7-14].

Contrast enhanced transthoracic echocardiography with saline (shaken to produce microbubbles $>10$ micrometer in diameter) is most practical method to detect pulmonary vascular dilatation $[14,15]$. After the administration of agitated saline in a peripheral vein in the arm,microbubble opacification of the the left atrium in 3-6 cardiac cycles after right atrial opacification indicates microbubble passage through an abnormally dilated vascular bed. Microbubble does not pass through normal capillaries (8-15 micrometer in diameter). This qualitatitve approach is more sensitive and less invasive than the injection of technetium-99-labeled microaggregated albumin in the peripheral vein for lung scan [15] with quantitative uptake in brain.However neither method can be used to discern discrete a-v communication from diffuse precapillary and capillary dilatation or intracardiac shunt. The former distinction can be made by pulmonary angiography. The latter distinction can be made by transesophageal contrast echocardiography that directly reveals the interatrial septum, identifies intratrial right to left shunt and shows passage of microbubbles entering the left atrium through atrial septal abnormality or pulmonary veins.

Pulmonary angiography is not necessary in most cases, but should be considered in the setting of severe hypoxemia $\left(\mathrm{PaO}_{2}<50 \mathrm{mmHg}\right)$ breathing room air when there exists a poor response to $100 \%$ inspired oxygen $\left(\mathrm{PaO}_{2}<300 \mathrm{mmHg}\right)$. The goal of angiography is to document discrete arteriovenous communications (usually $>5 \mathrm{~mm}$ in diameter) that could be embolized. Such embolization has resulted in significant improvement in oxygenation [7].

Pathogenesis of HPS may involve genetic disposition, an imbalance of pulmonary vascular endothelin A and B receptors, nitric oxide mediated vasodilatation and strong evidence for a neovascularization (angiogenesis) component of pulmonary vessels [9-11].

There are no proven pharmacologic treatment options in HPS that have resulted in sustained improvements in arterial oxygenation [7]. Transjugular intrahepatic portosystemic shunting (TIPS) has resulted in variable effects on arterial oxygenation based upon single case reports and, as such, is not considered a reliable or preferred long term treatment. Although rare, the hypoxemia of HPS associated with noncirrhotic portal hypertension, may significantly improve following interventional radiology approaches [1].

Once considered as an absolute contraindication for liver transplantation (LT), HPS is now considered to be an indication for LT in appropriate circumstances due to the extensive documentation for complete resolution of HPS and long-term survival with successful LT in both the pediatric and adult age groups. However, post-LT morbidity and mortality is not trivial $[12,13]$. 


\section{Conclusion}

Hepatopulmonary syndrome should be included in the differential diagnosis of unexplained hypoxemia with an evaluation of possible portal hypertension or liver disease even in the absence of other clinical symptoms.

\section{References}

1. Fallon MB, Abrams GA (2000) Pulmonary dysfunction in chronic liver disease. Hepatology 32: 859-865.

2. Schenk P, Fuhrmann V, Madl C, Funk G, Lehr S, et al. (2002) Hepatopulmonary syndrome: prevalence and predictive value of various cut offs for arterial oxygenation and their clinical consequences. Gut 51: 853-859.

3. Noli K, Solomon M, Golding F, Charron M, Ling SC (2008) Prevalence of hepatopulmonary syndrome in children. Pediatrics 121: e522-527.

4. Castro M, Krowka MJ (1996) Hepatopulmonary syndrome. A pulmonary vascular complication of liver disease. Clin Chest Med 17: 35-48.

5. De BK, Sen S, Biswas PK, Mandal SK, Das D, et al. (2002) Occurrence of hepatopulmonary syndrome in Budd-Chiari syndrome and the role of venous decompression. Gastroenterology 122: 897-903.

6. Arguedas MR, Abrams GA, Krowka MJ, Fallon MB (2003) Prospective evaluation of outcomes and predictors of mortality in patients with hepatopulmonary syndrome undergoing liver transplantation. Hepatology 37: 192-197.

7. Rodríguez-Roisin R, Krowka MJ (2008) Hepatopulmonary syndrome--a liverinduced lung vascular disorder. N Engl J Med 358: 2378-2387.
8. Kennedy TC, Knudson RJ (1977) Exercise-aggravated hypoxemia and orthodeoxia in cirrhosis. Chest 72: 305-309.

9. Zhang J, Ling Y, Tang L, Luo B, Pollock DM, et al. (2009) Attenuation of experimental hepatopulmonary syndrome in endothelin $B$ receptor-deficient rats. American Journal of Physiology - Gastrointestinal \& Liver Physiology 296: G704-G708.

10. Degano B, Mittaine M, Hervé P, Rami J, Kamar N, et al. (2009) Nitric oxide production by the alveolar compartment of the lungs in cirrhotic patients. Eur Respir J 34: 138-144.

11. Zhang J, Luo B, Tang L, Wang Y, Stockard CR, et al. (2009) Pulmonary angiogenesis in a rat model of hepatopulmonary syndrome. Gastroenterology 136: $1070-1080$

12. Krowka MJ, Porayko MK, Plevak DJ, Pappas SC, Steers JL, et al. (1997) Hepatopulmonary syndrome with progressive hypoxemia as an indication for liver transplantation: case reports and literature review. Mayo Clin Proc 72: 44-53.

13. Tumgor G, Arikan C, Yuksekkaya HA, Cakir M, Levent E, et al. (2008) Childhood cirrhosis, hepatopulmonary syndrome and liver transplantation. Pediatric Transplantation 12: 353-357.

14. Krowka MJ, Tajik AJ, Dickson ER, Weisner RH, Cortese DA (1990) Intrapulmonary vascular dilatation in liver transplant candidates: screening by two dimensional contrast echocardiography. Chest 97: 1165-1170.

15. Abrams GA, Nanda NC, Dubovsky EV, Krowka MJ, Fallon MB (1998) Use of macroaggregated albumin lung perfusion scan to diagnose hepatopulmonary syndrome: a new approach. Gastroenterology 114: 305-310. 